\title{
Fatigue Crack Arrest in Mild Steel via Iron Electroplating
}

\author{
Jiaming Huang ${ }^{1}$, Henry Cardenas ${ }^{2}$ \\ ${ }^{1}$ Taiji Group USA, Inc., Hickory, USA \\ ${ }^{2}$ Louisiana Tech University, Ruston, USA \\ Email: Cardenas@latech.edu
}

How to cite this paper: Huang, J. and Cardenas, H. (2021) Fatigue Crack Arrest in Mild Steel via Iron Electroplating. Materials Sciences and Applications, 12, 484-503. https://doi.org/10.4236/msa.2021.1211032

Received: July 20, 2021

Accepted: November 12, 2021

Published: November 15, 2021

Copyright $\odot 2021$ by author(s) and Scientific Research Publishing Inc. This work is licensed under the Creative Commons Attribution International License (CC BY 4.0). http://creativecommons.org/licenses/by/4.0/

\section{Open Access}

\begin{abstract}
In this work, electrochemical plating treatments were applied to ASTM A36 steel specimens to study the efficiency and limitations of this method for arresting fatigue crack propagation. Electroplated iron was deposited onto the crack surfaces using a circuit in which Swedish Iron served as the anode in a solution of Ammonium Iron(II) Sulfate Hexahydrate. The iron ions were driven into fatigue cracks that were formed within ASTM E399 compact tension specimens. This work showed that an iron-plating treatment operated at $20^{\circ} \mathrm{C}$ can arrest fatigue crack propagation for a significant period of cycles. The propagation re-initiation lives that resulted ranged from 11,000 to 230,000 cycles. As observed in prior work, the propagation re-initiation life correlated strongly to the magnitude of the stress intensity factor range that was applied during cycling. As this stress intensity increased, the propagation re-initiation life decreased. Repeated treatments on the same crack provided extended service lives by as much as 370,000 cycles or $60 \%$ of the entire fatigue life of the component. Future work may show that re-application of the treatment, when conducted prior to crack re-initiation, could further extend the service life indefinitely. The Correia crack closure model was modified to provide an empirical expression for predicting the crack re-initiation life of the treated component. Interestingly, highly effective arrest behavior was still observed for cracks that were loaded to stress intensity factors of only 3 - 6 $\mathrm{MPa} \sqrt{\mathrm{m}}$ during the treatment but then subjected to $20 \mathrm{MPa} \sqrt{\mathrm{m}}$ during cyclic loading. Galvanic corrosion of the plated material exposed to simulated seawater was estimated to be 3 mpy. Future work will examine the use of less active plating alloys and the possibility of applying effective treatments into cracks that are in an unloaded state.
\end{abstract}

\section{Keywords}

Fatigue, Crack Closure, Crack Propagation, Iron Plating, Electrochemical Treatment, Galvanic Corrosion 


\section{Introduction}

Metal fatigue is a progressive damage process that leads to crack formation and growth caused by cyclic loading [1] [2]. It tends to begin at surface irregularities and stress concentration points. It is a complicated metallurgical process that is difficult to accurately describe and model on a microscopic level. Under cyclic loading, cracks can initiate at stress levels that are much lower than the yield strength of the material. Once initiated, a crack will continue to grow during each loading cycle until it reaches a critical size that results in failure [1]. Crack initiation and propagation are largely controlled by the tensile component of the applied stress but can be greatly influenced by environmental factors that impact the crack surfaces, especially in the vicinity of the crack tip. In this study, an electrochemical treatment was developed to stop fatigue crack propagation in A36 mild steel. This work specifically focused on the electro-deposition of iron onto the surfaces of open cracks.

Electroless plating of crack surfaces applied to thin sections $(3.5-8 \mathrm{~mm})$ of aluminum and AISI 4130 low-alloy steel were investigated by Shin, Chen, Song, Sheu and Chou [3] [4]. Dissimilar metals such as nickel and copper were mechanically infiltrated. Significant amounts of crack arrest were observed that depended in part on crack overloading conducted during the deposition process. Crack wedge modeling developed in this work focused on the prediction of post-treatment crack propagation rates and worked well without incorporation of the plated-material properties. Dimensional parameters of the model were acquired from X-ray analysis. In later work applied to thicker $(2 \mathrm{~cm})$ sections of mild steel, Dolgan also found that electrodeposition of nickel (Ni) onto the surfaces of the cracks caused the arrest of fatigue crack propagation [5]. To minimize the impact of galvanic corrosion resulting from the dissimilarity of $\mathrm{Ni}$ and $\mathrm{Fe}$, Shrestha and Cardenas studied the galvanic corrosion behavior that resulted when iron was plated onto mild steel [6]. This work found that the plated iron sacrificially protected the mild steel from corrosion. In contrast, the nickel-plating from the earlier work was tending to drive the corrosion of the steel substrate. Dolgan and Cardenas further observed that nickel-plating was well correlated to the stress intensity factor range that was applied during load cycling. A model based on a crack surface adhesion theory also exhibited a reasonably useful prediction of crack re-initiation but was highly empirical. As noted earlier, the nickel-plating approach exhibited the potential for galvanic corrosion to cause damage to the base metal. The current work examined the alternative of plating iron into the fatigue crack and using a semi-empirical crack closure model to assist in the prediction of crack re-initiation.

\section{Background}

The following sections examine several key elements that motivate and guide the approach used in this study. The primary background element is the modeling and prediction of fatigue crack growth and the highly influential concept of 
crack closure. This section also includes concepts on electroplating and dissimilar metal corrosion.

\subsection{Fatigue Crack Growth}

The most widely accepted equation used to characterize the crack growth behavior was obtained by Paris [7]. The Paris Law has the form,

$$
\frac{\mathrm{d} a}{\mathrm{~d} N}=C(\Delta K)^{m}
$$

where $a$ is the crack length, $N$ is the number of loading cycles, $C$ and $m$ are empirical material constants and $\Delta K$ is the stress intensity factor range, $\Delta K=K_{\max }-$ $K_{\min }$. The fundamental crack growth behavior of metals can be divided into three distinct regions: Slow crack growth, Power law growth, and final failure [1] [7]. Slow crack growth is a crack propagation phenomenon that is difficult to predict since it is highly dependent on microstructure, environment, and material properties whose interplay is not well understood. At low-stress intensity factors, fatigue crack behavior is bounded by a threshold value $\Delta K_{\mathrm{th}}$, below which there is no crack growth. The $\Delta K_{\mathrm{th}}$ value for steels found in the literature is typically between 5 and $15 \mathrm{MPa} \sqrt{\mathrm{m}}$ [3] [6]. For larger magnitudes of $\Delta K$, the crack growth is governed by the Paris Law. Near the end of the service life, the crack propagation can become unstable and extremely rapid [8] [9]. Crack growth of this nature is largely controlled by the fracture toughness of the material, $K_{c}$ Forman's equation is a modification of the Paris Law that incorporates this fracture toughness as well as the mean stress [10] [11]. It governs the rapid crack growth behavior observed near the end of service life and has the form,

$$
\frac{\mathrm{d} a}{\mathrm{~d} N}=\frac{C \Delta K^{m}}{(1-R) K_{c}-\Delta K},
$$

where $R$ is the stress ratio $\left(R=\frac{\sigma_{\min }}{\sigma_{\max }}\right)$, and $K_{c}$ is the critical fracture toughness value at which catastrophic fracture can occur.

\subsection{Crack Closure}

Crack closure is a phenomenon characterized by the surfaces of fatigue cracks remaining closed even as a tensile load is being applied [12] [13]. It was first described by Elber in 1970. Elber found that significant contact between the fracture surfaces was occurring due to the plastic deformation. He proposed that this contact of crack surfaces was the result of permanent deformation occurring within a plastic zone that forms at the crack tip where the yield stress of the material is being exceeded. This yielded region of material causes the fatigue crack to remain closed when the applied load is still in tension. The crack will not open again until a sufficiently high stress is applied. Related to this concept, Elber also introduced the idea of a crack-opening stress [12]. Crack-opening stress is the value of the applied stress at which the crack just becomes fully open. $\mathrm{He}$ demonstrated that to make fatigue crack growth occur, the crack must become 
fully open via an applied stress that is greater than the crack-opening stress. That work introduced the concept of an effective $\Delta K$ value that defined the stress intensity factor range during which a crack remained open. For the determination of the effective $\Delta K$, the stress intensity factors at maximum load $\left(K_{\max }\right)$ and at crack opening $\left(K_{\text {open }}\right)$ need to be known [12] [13] [14]. These parameters were used to define an effective stress intensity factor range that is given by,

$$
\Delta K_{\text {eff }}=K_{\max }-K_{\text {open }} .
$$

Revisiting the Paris Law (Equation (1)), the fatigue crack growth rate, $\mathrm{d} a / \mathrm{d} N$, according to Elber, was now a function of the effective stress intensity factor range, $\Delta K_{\text {eff }}$ The crack closure concept has often been used to explain the stress ratio effect. This is also known as the $R$ ratio, where $R=\frac{\sigma_{\min }}{\sigma_{\max }}$. Crack closure has also been used to explain temperature and corrosion effects on $\Delta K_{\mathrm{th}}$ [15]. Elber also suggested that $\Delta K_{\text {eff }}$ is dependent on the $R$ ratio.

In general, a higher $R$ ratio value often results in less crack closure and a higher $\Delta K_{\text {eff }}$ value. Elber's empirical relationship between $R$ ratio and the effective stress intensity factor range is given by [12],

$$
U=\frac{\Delta K_{\mathrm{eff}}}{\Delta K}=0.5+0.4 R \text {. }
$$

Note this equation is only valid for $R>0$. Another crack closure model of more expanded applicability was introduced by Schijve in 2004 [16]. It has the form,

$$
U=0.55+0.33 R+0.12 R^{2},(-1 \leq R<1)
$$

A more recent empirical model that also incorporates the $\Delta K_{\mathrm{th}}$ was proposed by Correia in 2016 [17]. To obtain $\Delta K_{\text {eff }}$, the parameter $U$ provided by Correia was presented as,

$$
U=\left(1-\frac{\Delta K_{\mathrm{th}, \mathrm{o}}}{K_{\max }}\right)(1-R)^{\gamma-1},
$$

where $\Delta K_{\mathrm{th}, \mathrm{o}}$ is the threshold value of stress intensity range at $R=0$, and $\gamma$ is a material parameter obtained from crack propagation experiments and viewed as dependent on "measurements location and measurements sensitivity". By its association with crack tip plasticity, it is conceivable that $\gamma$ may also carry some level of material plasticity impact.

Crack growth in the vicinity of threshold values is relatively slow and difficult to predict. For metallurgically small cracks on the order of defect sizes the threshold stress intensity value for crack propagation $\left(\Delta K_{\text {theff }}\right)$ is considered intrinsic to the material and largely dependent upon bond elasticity [18] [19] [20]. This behavior has been found to be proportional to the Young's Modulus. Longer cracks exhibit extrinsic influences from the crack flanks that can cause variable growth rates as well as crack arrest that is highly dependent upon the stress intensity factor as well as the length of the crack that is emanating from a notch or 
defect. The crack flank phenomena that influences crack growth rates includes residual stress (from notches and overloads), plasticity-induced wedging, surface roughness-induced friction, environmentally induced oxide formation/wedging [21]. The plasticity, roughness, and oxide formation are influenced by grain size, crystal lattice orientation, and lattice distortion due to alloying. Cracks can reach a length at which these extrinsic influences upon the growth rate are no longer dependent upon the length of the crack [18]. At this point the threshold value of the stress intensity value $\Delta K_{\mathrm{TH}}$ is no longer a function of the crack length because the crack flank influences (such as the plasticity-induced wedging) are fully developed. A mathematical function referred to as the R-curve is an empirical relationship that defines threshold values (as a function of crack length) that occur between the intrinsic threshold $\left(\Delta K_{\mathrm{th}, \mathrm{eff}}\right)$ and the extrinsic threshold $\left(\Delta K_{\mathrm{th}}\right)$ values. No standard approach for developing this function currently exists. More research (especially regarding oxide influences) is needed to make this curve relatively convenient to obtain with reasonable precision [22].

\subsection{Electrochemical Deposition and Layer Interactions}

Electrochemical deposition is a process by which a metal layer is deposited onto the surface of a conductive substrate by reducing the dissolved metal ions out from the electrolytic solution [23] [24] [25]. Plating treatments require a ready source of metal ions that are in solution. A sacrificial metal can serve as a source of ions. It thus serves as an anode. A substrate metal can serve as a cathode that receives the plated layer. The primary application of electrochemical deposition is to change the surface properties of the component. This may typically include changes to corrosion resistance, wear resistance, and aesthetic quality.

According to Faraday's law of electrolysis, the amount of material deposited onto a substrate is proportional to the amount of electric current applied [25]. Faraday's law has the form,

$$
W=\frac{I t A}{n F},
$$

where $W$ is the weight of the plated metal in grams, $I$ is the current in amperes, $t$ is time in seconds, $n$ is the valence of the dissolved metal in solution, $A$ is the atomic weight and $F$ is Faraday's constant ( $F=96,485.309$ coulombs/equivalent). The electrodeposition process can be affected by temperature, $\mathrm{pH}$ level, current density, and the presence of other ions present in the plating solution [25].

When metals are plated onto dissimilar metallic substrates, galvanic corrosion can arise from the new arrangement [26]. Under these circumstances, one of the metals behaves more actively (or anodic) and will corrode sacrificially, while the other metal behaves in a more noble (or cathodic) manner that effectively protects it from corrosion. The driving force for the accelerated corrosion of the anodic metal is the galvanic potential difference which is a voltage reading that can be measured between these two metals. In general, a smaller galvanic potential reading would tend to indicate a lower likelihood of a significant corrosion rate being suffered by the anodic metal. 


\section{Methodology and Procedures}

Repeated fatigue tests were conducted using compact tension (CT) specimens as defined in ASTM E399 [27]. (See Figure 1) The specimens consisted of ASTM A36 mild (low carbon) steel. Fatigue cycling was conducted using an MTS servo-hydraulic testing machine. The machine was controlled using TestStar ${ }^{\mathrm{TM}}$ IIs system (MTS Systems Corporation, MN, USA). The cycling load was administered in a constant amplitude sinusoidal pattern at $2 \mathrm{~Hz}$, with a stress ratio $(R)$ in the range of $0.1-0.3$. The maximum stress intensity $(K)$ and the $\Delta K$ were permitted to increase as the cracks grew. The values used for the initial $\Delta K$ applied to the uncracked notch ranged from $19 \mathrm{MPa} \sqrt{\mathrm{m}}$ to $29 \mathrm{MPa} \sqrt{\mathrm{m}}$.

The crack treatments were conducted after cracks were formed as shown in Figure 1. A static loading armature was used to apply a force $(F)$ to achieve a crack mouth opening displacement that correlated to a stress intensity factor of approximately $3 \mathrm{MPa} \sqrt{\mathrm{m}}$. When possible, repeat treatments were provided after crack propagation had resumed. These repeat treatments were provided while the cracks were statically loaded at stress intensity values in the range of 3 6.5 $\mathrm{MPa} \sqrt{\mathrm{m}}$. These $K$ values constituted approximately $10 \%-15 \%$ of the $\Delta K$ values that were later applied during subsequent fatigue cycling. The bath solution consisted of Ammonium Iron (II) Sulfate Hexahydrate $\left(\left(\mathrm{NH}_{4}\right)_{2} \mathrm{Fe}\left(\mathrm{SO}_{4}\right)_{2} \cdot 6 \mathrm{H}_{2} \mathrm{O}\right)$ in de-ionized (DI) water [6]. The dosage was close to the maximum solubility (of 300 gram/liter) at $20^{\circ} \mathrm{C}$. The $\mathrm{pH}$ in the bath started in the range of $5.0-5.5$. After the 60-minute treatment the ending $\mathrm{pH}$ was in the vicinity of 6.0. Each specimen was plated with a constant D.C. current density of $0.02 \mathrm{~A} / \mathrm{cm}^{2}$ at $20^{\circ} \mathrm{C}$. The voltage required to achieve this current density was in the ranged of $1-2 \mathrm{~V}$. The plating surface area was calculated using the plated notch and fatigue crack length (that was covered by the treatment solution), and the thickness of the specimen.

Following treatment each specimen was fatigue cycled with the same magnitude and frequency of loading as was applied during the crack initiation process. These specific $\Delta K$ values are noted in Figure 4. Post-treatment, the load cycling was continued until crack propagation resumed. In most cases, the re-initiated

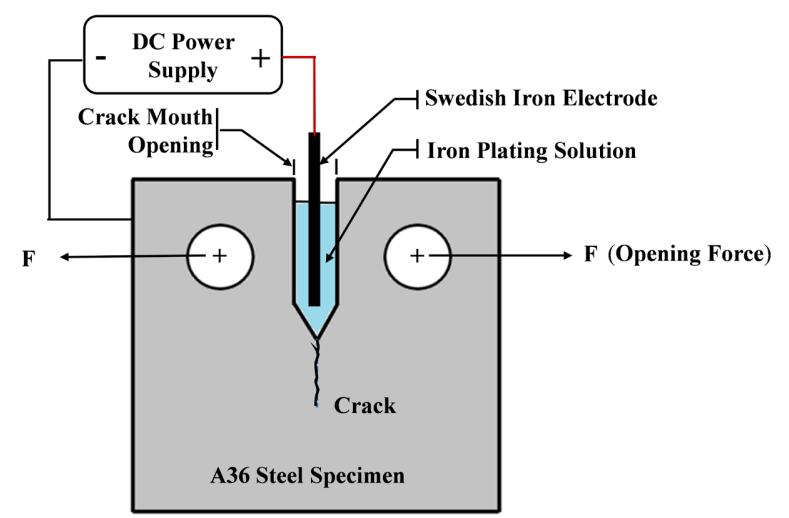

Figure 1. Schematic of electrochemical fatigue crack treatment. 
fatigue cracks were subjected to one or more additional treatments in order to study the effectiveness of repeated treatments.

Galvanic corrosion potential and current measurements were conducted to assess the corrosion compatibility of the plated material with respect to the base metal. The galvanic potential was measured using a high impedance voltmeter [28] [29]. Both electrodes were submerged in $3.5 \mathrm{wt} \% \mathrm{NaCl}$ solution at $20^{\circ} \mathrm{C}$. The Swedish iron electrode was a cylindrical bar with a diameter of $1 \mathrm{~cm}$ and a length of $1.5 \mathrm{~cm}$, while the bare A36 steel was a flat bar with dimensions of 2.5 $\mathrm{cm} \times 2 \mathrm{~cm} \times 1.5 \mathrm{~cm}$. These two electrodes were spaced $5 \mathrm{~cm}$ apart in the simulated seawater solution. To avoid polarization error, the readings were recorded immediately after completing the circuit. The galvanic current was measured using a zero-resistance ammeter [28] [29]. The test setup consisted of a power supply, a voltmeter, an ammeter, a plated iron electrode and an A36 steel electrode. The electrodes (as described earlier) were immersed in simulated seawater solution $(3.5 \mathrm{wt} \% \mathrm{NaCl})$ at $20^{\circ} \mathrm{C}$. To overcome the inherent resistance of the ammeter, the power supply was adjusted until the circuit resistance reading was zero. The current read from the ammeter at that (zero-reading) moment was recorded. 6 trials were conducted for all measurements.

\section{Results and Discussion}

In the following sections, the electrochemical treatment impact on extending the fatigue crack propagation life of A36 steel specimens was examined. A modified Correia's crack closure model was developed and compared to the crack re-initiation life observed. The corrosion behavior of the plated metal was also examined.

\subsection{Fatigue Crack Treatment Response}

To study the fatigue crack growth behavior after electrochemical treatment, compact-tension specimens were tested using the MTS servo-hydraulic testing machine as described earlier in accordance with ASTM E399. In most cases the treatments were repeated after the crack propagation had reinitiated.

During this study, the fatigue crack initiation life from the notch exhibited a wide range of behavior. For example, one crack initiated at 17,000 cycles under a $\Delta K$ value of $30 \mathrm{MPa} \sqrt{\mathrm{m}}$. Another crack initiated at 350,000 cycles under lower stress with a $\Delta K$ value of $19 \mathrm{MPa} \sqrt{\mathrm{m}}$. The $R$ values for each specimen were within the range of 0.1 to 0.3 . The cracks were initially treated when crack lengths ranged from 2.13 to $4.22 \mathrm{~cm}$. The corresponding $\Delta K$ values for these cases ranged from 28 to $33 \mathrm{MPa} \sqrt{\mathrm{m}}$. In each case, the first $1.9 \mathrm{~cm}$ of the crack length consisted of the E399 notch. This meant that the actual length of the fatigue crack that initially received treatment ranged from 0.22 to $2.3 \mathrm{~cm}$.

An example of the fatigue crack behavior following electrochemical treatment is shown in Figure 2. The crack started propagating at 145,000 cycles, and the first electrochemical treatment was performed at 170,000 cycles at a crack length of $2.67 \mathrm{~cm}$ and a $\Delta K$ of $28 \mathrm{MPa} \sqrt{\mathrm{m}}$. Following this treatment, the crack 


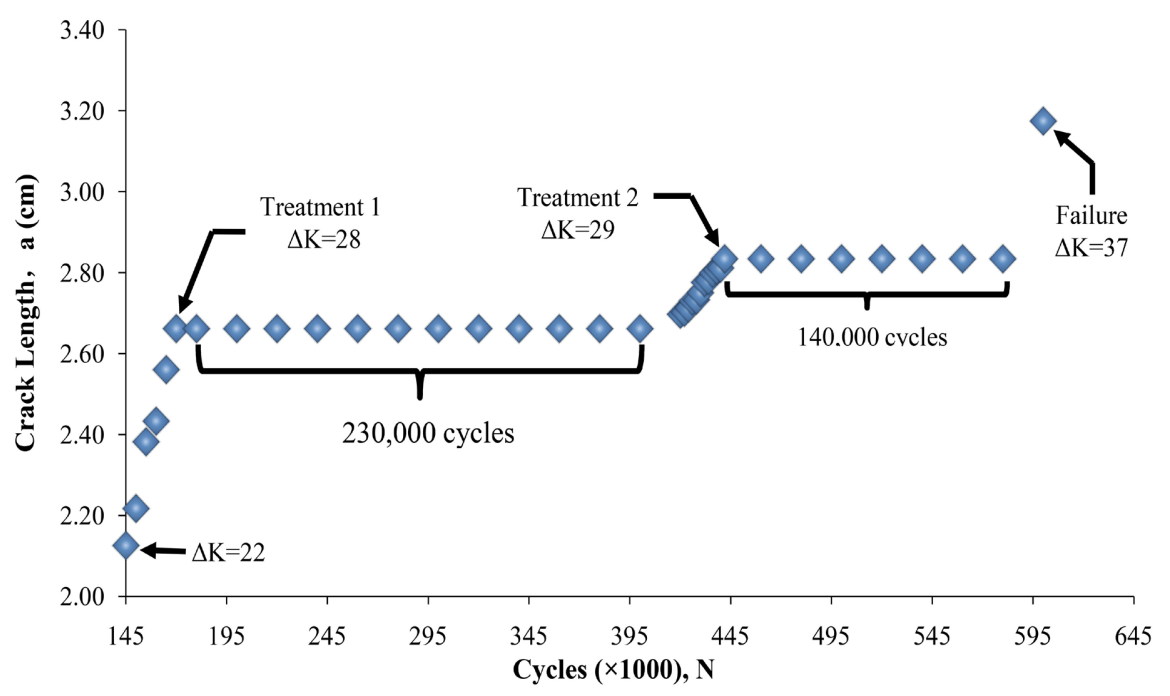

Figure 2. Fatigue crack propagation of a typical E399 low carbon steel specimen with two electrochemical treatments shown. Both treatments caused crack arrest for over $10^{5}$ cycles.

propagation halted for 230,000 cycles. Another treatment was applied after the crack reached $2.84 \mathrm{~cm}$ at 440,000 cycles and a $\Delta K$ value of $29 \mathrm{MPa} \sqrt{\mathrm{m}}$. The crack propagation was arrested for 140,000 cycles after this $2^{\text {nd }}$ treatment. After the $2^{\text {nd }}$ crack re-initiation, failure occurred at 600,000 cycles and a $\Delta K$ value of 37 $\mathrm{MPa} \sqrt{\mathrm{m}}$. The entire fatigue life of this specimen was approximately 600,000 cycles.

The fracture surface of this specimen is presented in Figure 3. The dashed line A indicates the location of the initial crack tip at the notch at the start of load cycling. Position B is where Treatment 1 was performed at 170,000 cycles. The crack was arrested for 230,000 cycles. The area between A and B was the fatigue crack area that received this initial treatment. This area exhibited iron oxide discoloration that developed during cyclic loading. Location $\mathrm{C}$ is the crack tip location when Treatment 2 was applied at 440,000 cycles. Following this treatment, the crack was arrested for 140,000 cycles. The area between B and C is the surface of the treated iron that was partially covered with iron oxide. Location $\mathrm{D}$ is the surface of the fracture that was observed at failure at 600,000 cycles when the $\Delta K$ reached $37 \mathrm{MPa} \sqrt{\mathrm{m}}$.

As noted above, the total fatigue life of this specimen was 600,000 cycles. The crack started propagating at 145,000 cycles. The total fatigue life was extended by 370,000 cycles or approximately $60 \%$ due to the two plating crack treatments. The two treatments succeeded in arresting the crack propagation for 230,000 cycles and 140,000 cycles respectively. Based on these observations, it appears that this treatment can extend the fatigue service life of low carbon steel both significantly and repeatedly.

The fracture surface shown in Figure 3 exhibited two major areas of particular interest. One is the plated iron area (from Location A to C) which exhibited 


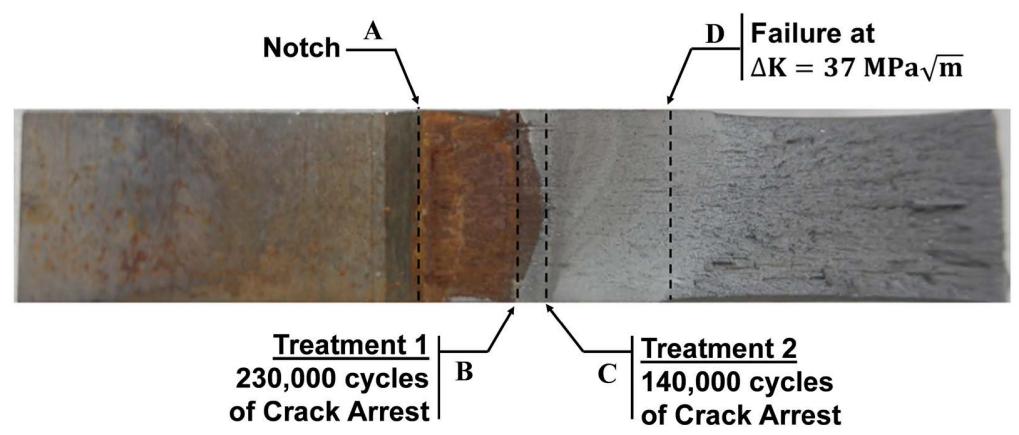

Figure 3. Fracture surface of the treated specimen from Figure 2. (A: Initial Crack Tip Location; B: Crack Tip Location where Treatment 1 was performed; C: Crack Tip Location where Treatment 2 was performed; D: Location of the start of fracture instability).

corrosion from exposure to moisture for an extended period during cyclic loading. The corrosion products covered a significant portion of the crack surface. Currently, it is indeterminate if the corrosion product formation was helping the crack re-initiation life or reducing it. This question is addressed further in the corrosion susceptibility section that follows and will be further examined in future work. A feasible approach for this future work could involve both treating and cycling in an anaerobic environment, such as a nitrogen atmosphere. In general, there is need to study the impact of corrosion on a treated crack by comparing the behavior of crack re-initiation and propagation under various corrosive environments, $\Delta K$ values, and $R$ ratios.

The crack re-initiation life of each specimen as related to the applied $\Delta K$ (as opposed to $\left.\Delta K_{\text {eff }}\right)$ is presented in Figure 4 . The correlation coefficient ( $R^{2}$ value) of the exponential trend line was 0.82 . This indicated a strong relationship between the crack arrest life and the corresponding $\Delta K$ level at the time of treatment. It was interesting to find that at a lower $\Delta K$ level the treatment tended to provide a relatively higher crack re-initiation life. According to Elber's crack closure theory, a lower $\Delta K$ level (for the same $R$ value) would generally help the crack to remain closed during more of a given load cycle [12] [13]. This observation bears a significant implication for getting optimal treatment benefit. It appears that treating cracks at relatively low $\Delta K$ levels may result in higher crack re-initiation lives. This trend implies a time/cycle-dependent degradation of the treatment and its impact on crack closure, i.e. $\Delta K_{\text {eff }}$ Possible reasons for this trend are discussed in a later section.

During cyclic loading, it was observed that a treated crack restarted propagation even when $\Delta K_{\text {eff }}$ was relatively close to the fatigue threshold value of 15 $\mathrm{MPa} \sqrt{\mathrm{m}}$ [6]. The crack closure obtained in this work only temporarily caused cracks to remain closed. It is possible that threshold values of $\Delta K_{\mathrm{th}}$ present in the current study may differ from literature-reported values ranging from 5 to 15 $\mathrm{MPa} \sqrt{\mathrm{m}}$ [30]. It is conceivable that localized dislocation formation along fatigue crack surfaces during cycling could deteriorate the impact of crack closure. This notion is further explored in the modeling section of this study. 


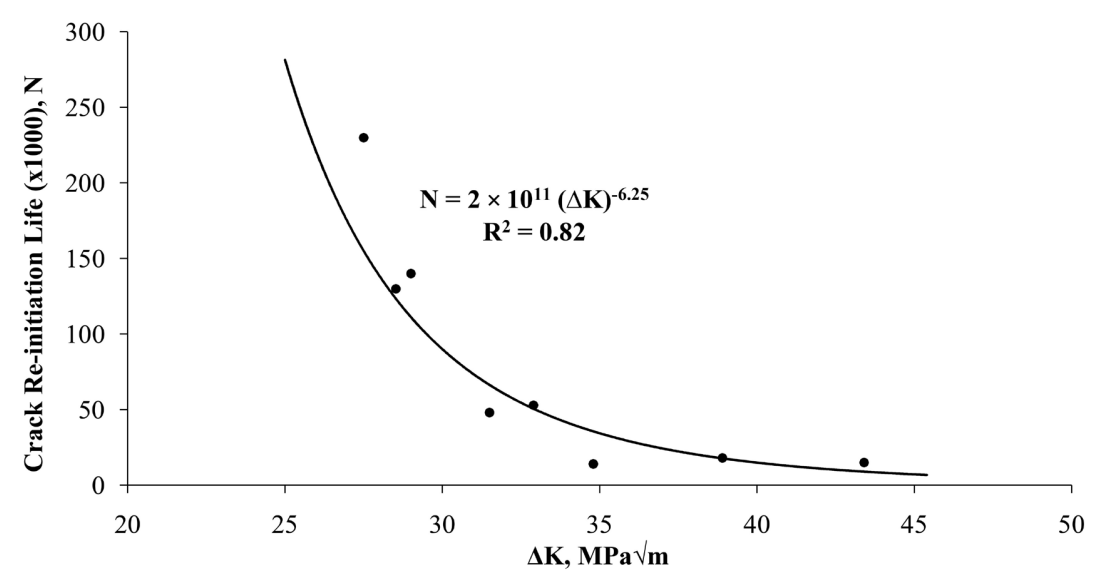

Figure 4. Fatigue crack re-initiation life for treatments conducted at various $\Delta K$ values.

Figure 5 shows the crack behavior of a specimen that was treated on three separate occasions during cyclic loading. The stress ratio $R$ for this specimen was approximately 0.23 . The average crack growth rate for the entire test was about $10^{-7} \mathrm{~m} /$ cycle. The three treatments collectively provided a fatigue crack propagation life extension of 63,000 cycles, which was approximately $15 \%$ of the entire life of the specimen.

Paris' Law (Equation (1)) was used to compare the current findings with anticipated crack growth behavior from the literature. The coefficients of the Paris Law, obtained from the literature, were specific to ASTM A36 steel. These values were $C \approx 7 \times 10^{-10}$ and $m \approx 3[31]$.

The average crack growth rate before Treatment 1 was $3.2 \times 10^{-7} \mathrm{~m} / \mathrm{cycle}$. This agreed well with the Paris Law model as shown in Figure 5. The first electrochemical treatment was performed at 390,000 cycles when the crack had reached $3.33 \mathrm{~cm}$ and the stress intensity factor range, $\Delta K$, was equal to $32 \mathrm{MPa} \sqrt{\mathrm{m}}$. After Treatment 1 , there was no crack growth observed for 48,000 cycles. The crack growth rate after the crack had re-initiated was approximately $1.9 \times 10^{-7}$ $\mathrm{m} /$ cycle. The second treatment was applied at 471,000 cycles when the crack was $4.22 \mathrm{~cm}$ and $\Delta K$ was $43 \mathrm{MPa} \sqrt{\mathrm{m}}$. After this treatment, the crack was arrested for 18,000 cycles. The crack started growing again at 489,000 cycles and the third treatment was performed at 490,000 cycles at $\Delta K=59 \mathrm{MPa} \sqrt{\mathrm{m}}$. This time, the crack propagation was not arrested by the third treatment. The specimen proceeded to fail at 498,000 cycles at $\Delta K=75 \mathrm{MPa} \sqrt{\mathrm{m}}$.

Based on observations from Figure 5, the third treatment was ineffective. The crack kept growing rapidly and failed within 8000 cycles. The value of the plain strain fracture toughness $\left(K_{\mathrm{IC}}\right)$ for ASTM A36 steel reported in the literature ranges from $45 \mathrm{MPa} \sqrt{\mathrm{m}}$ to $67 \mathrm{MPa} \sqrt{\mathrm{m}}$ [30]. When the third treatment was applied, the $\Delta K$ value (59 $\mathrm{MPa} \sqrt{\mathrm{m}}$ ) was in this range, thus making it reasonable for fracture to be imminent. This last treatment was attempted in the final fracture region of crack growth, when the $\Delta K$ value was in the range of possible $K_{\mathrm{IC}}$ values for this material. According to the Forman model (Equation (2)) this region of crack growth is not governed by $\Delta K_{\text {eff. }}$ This suggests that crack closure 
is not playing a significant role in crack growth. These observations appear to indicate that relatively low plating treatment dosages may be ineffective in cases where $\Delta K$ is in the vicinity of $K_{\text {IC }}$ and crack closure effects generally have little influence.

As calculated using the Paris Law, Specimen 3 from Figure 5 was expected to fail within 430,000 cycles. Following two treatments, the fatigue life of this specimen was extended by 68,200 cycles, which constituted approximately $13 \%$ of the entire propagation life. Table 1 lists the fatigue life extension and the number of treatments applied to each specimen of the current study. It was observed that for E399 low carbon steel, applying the iron plating treatment repeatedly could significantly extend the crack propagation life and delay final failure.

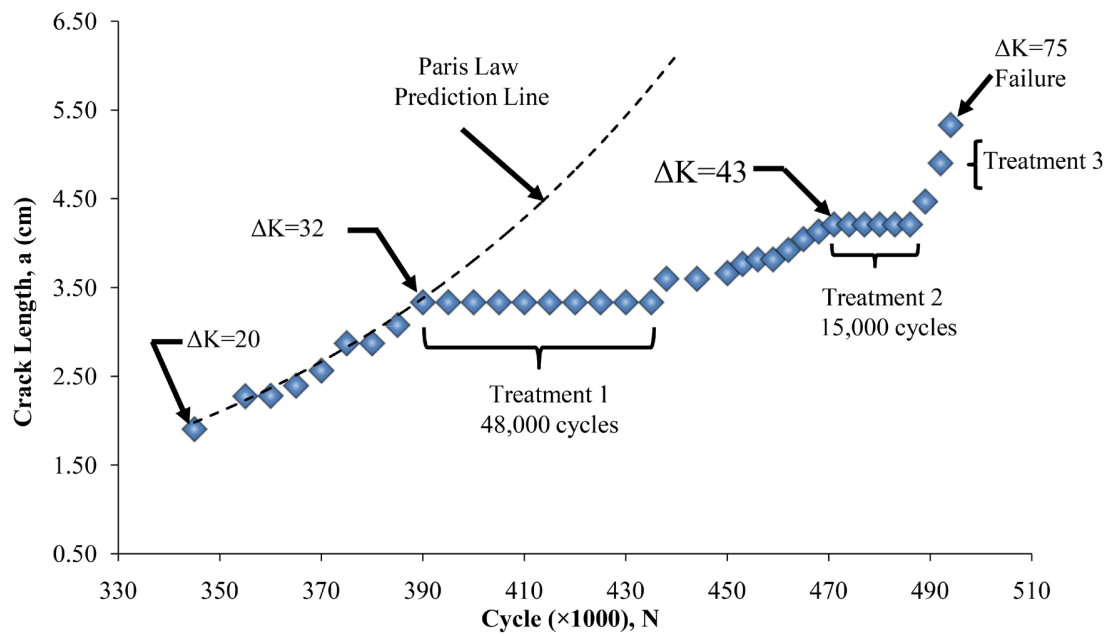

Figure 5. Fatigue crack propagation of a specimen that was treated on three occasions during cyclic loading. The dashed line represents the fatigue crack behavior predicted by the Paris Law.

Table 1. Fatigue life extension due to iron plating.

\begin{tabular}{|c|c|c|c|c|c|}
\hline Specimen & Treatment & $\begin{array}{c}\text { Re-initiation } \\
\text { Life } \\
\text { (cycles) }\end{array}$ & $\begin{array}{c}\text { Total } \\
\text { Re-initiation Life } \\
\text { (cycles) }\end{array}$ & $\begin{array}{l}\text { Total } \\
\text { Fatigue Life } \\
\text { (cycles) }\end{array}$ & $\begin{array}{c}\text { Life } \\
\text { Extension } \\
\quad(\%)\end{array}$ \\
\hline 1 & $1 \mathrm{st}$ & 11,000 & 11,000 & 63,000 & 17 \\
\hline \multirow{2}{*}{2} & $1 \mathrm{st}$ & 230,000 & \multirow{2}{*}{370,000} & \multirow{2}{*}{587,000} & \multirow{2}{*}{60} \\
\hline & $2 \mathrm{nd}$ & 140,000 & & & \\
\hline \multirow{3}{*}{3} & $1 \mathrm{st}$ & 48,000 & \multirow{3}{*}{63,000} & \multirow{3}{*}{498,000} & \multirow{3}{*}{13} \\
\hline & 2nd & 15,000 & & & \\
\hline & $3 r d$ & 0 & & & \\
\hline \multirow{2}{*}{4} & $1 \mathrm{st}$ & 53,000 & \multirow{2}{*}{71,000} & \multirow{2}{*}{728,000} & \multirow{2}{*}{10} \\
\hline & 2nd & 18,000 & & & \\
\hline \multirow{2}{*}{5} & $1 \mathrm{st}$ & 130,000 & \multirow[t]{2}{*}{144,000} & \multirow[t]{2}{*}{794,000} & \multirow[t]{2}{*}{18} \\
\hline & $2 \mathrm{nd}$ & 14,000 & & & \\
\hline
\end{tabular}


As shown in Table 1, the extended fatigue life achieved for each specimen ranged from $10 \%-60 \%$. It is interesting to note that the possibility that a treatment could be applied prior to crack re-initiation. Doing so could further delay crack re-initiation. This approach could be useful in the maintenance of fatigue sensitive systems. Timely re-application of iron plating treatment could conceivably cause cracks to remain arrested indefinitely. Hence, predicting the re-initiation life becomes a crucial precondition for implementing this approach effectively. A theoretical model for crack re-initiation prediction is developed in the following section.

\subsection{Fatigue Crack Re-Initiation Life Modeling}

As illustrated in Figure 4, it was observed that the number of cycles required for re-initiating a fatigue crack decreased as $\Delta K$ increased. With this governing relationship in hand, it is possible to obtain a useful correlation between the crack re-initiation cycles and the effective stress intensity factor range $\left(\Delta K_{\text {eff }}\right)$ at the time of treatment. A theoretical model taking into account crack closure, mean stress, and the effects of a plating treatment can be based on the Correia model (Equation (6)). A modified version of the Correia equation can have the form,

$$
\frac{\Delta K_{\mathrm{eff}}}{\Delta K}=\left(1-\frac{\Delta K_{\mathrm{th}, \mathrm{o}}}{K_{\max }}\right)(1-R)^{(\gamma+\alpha-1)},
$$

where $\Delta K_{\text {eff }}$ is the effective stress intensity factor following treatment, $\Delta K_{\mathrm{th}, \mathrm{o}}$ is the threshold value of the stress intensity range at $R=0, R$ is the stress ratio $\left(\frac{\sigma_{\min }}{\sigma_{\max }}\right), \gamma$ is a material parameter related to specific $K$ value thresholds introduced by Correia [17]. A A modification to address plating impact can be provided by the factor $\alpha$. This $\alpha$ factor can be related to the effect that the plating treatment has on the crack surfaces. To define a quantitative value of $\alpha$, the deposition of the plated iron in the crack was assumed to be a uniformly thin layer as shown in Figure 6.

To start with, the model would be useful if it could relate to the relative height of fatigue striations (See Figure 6). A relatively tall striation height would tend to cause cracks to be closed for a greater portion of the load cycle. A key property of the striated material (and the plating) would be the tendency for plasticity

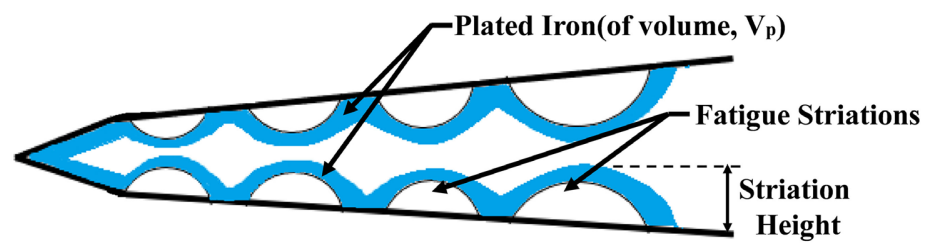

Figure 6. Conceptual schematic of a treated fatigue crack showing a representation of fatigue striation topography that could be influenced by iron plating. The $\alpha$ factor was conceived as a parameter that influences this topography and thus the impact that a given treatment can have on crack closure. 
and hardening to influence the impact of the striation height increase. Presumably, as striation height is gradually diminished, the extent of crack closure (as conveyed by the magnitude of $\Delta K_{\text {eff }}$ ) would also be diminished. It is possible to quantify the treatment influence on striation height in terms of the volume of material that is distributed via plating over the crack surface. The time-dependent response of the newly deposited material to crack closure could then be tied to plasticity and hardness. The influence of these factors may be estimated by the ultimate tensile strength of the material. Changes to striation height are related to the volume of plated iron $\left(V_{p}\right)$ delivered by the treatment. A treatment effectiveness factor $(\alpha)$, may then be estimated by calculating the decimal volume fraction of the plated material $\left(V_{p}\right)$ with respect to the volume of the crack $\left(V_{c}\right)$ and combining it with a similar ratio of the ultimate tensile strengths of each material. An expression for $\alpha$, could thus have the form,

$$
\alpha=\frac{V_{P}}{V_{C}} \cdot \frac{\sigma_{\mathrm{UTP}}}{\sigma_{\mathrm{UTB}}},
$$

where $V_{P}$ is the volume of the plated material, $V_{C}$ is the volume of the crack, $\sigma_{\text {UTP }}$ is the ultimate tensile strength of plated material and $\sigma_{\mathrm{UTB}}$ is the ultimate tensile strength of base material.

Regarding Equations (8) and (9), a higher ratio of $V_{P} / V_{C}$ would tend to cause the fatigue crack to exhibit a more extended period of closure, since increasing $a$ corresponds to a relatively smaller $\Delta K_{\text {eff }}$ For a plated material that is softer than the base material, the softness of the plasticity would tend to reduce the benefit from the ratio of $V_{P} / V_{C}$. This is because localized yielding occurring at striation contact points would tend to reduce the plated striation height. With these striation heights reducing over time, this would tend to reduce the period of crack closure over time. This would be accompanied by $\Delta K_{\text {eff }}$ increasing over time until the crack finally resumes propagation.

The volume calculation of a fatigue crack was estimated by modeling it as a triangle wedge (Figure 7). Utilizing the crack length (a), the crack mouth opening displacement $(b)$, and the thickness of the specimen $(B)$, the crack volume $\left(V_{C}\right)$ was then found by,

$$
V_{C}=\frac{a b}{2} B
$$

The volume of plated material may be calculated using Faraday's law (as introduced in the background) and the material density. In this study, the ratio of $V_{P} / V_{C}$ varied from $10 \%$ to $20 \%$. The ultimate tensile strength of Swedish Iron

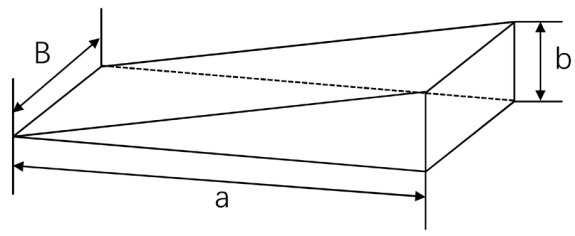

Figure 7. Volume parameters of a fatigue crack. 
and A36 Steel are $540 \mathrm{MPa}$ and $550 \mathrm{MPa}$ respectively [28]. From Equations (9) and (10), it was found that $\alpha$ ranged from 0.1 to 0.2 . From the literature, $\gamma=0.9$ [17].

After obtaining the $\Delta K_{\text {eff }}$ from the modified Correia model, the number of cycles to re-initiate fatigue crack propagation was estimated using an empirically derived curve of the form,

$$
N_{\text {re }}=A\left(\Delta K_{\text {eff }}\right)^{B} \text {, }
$$

where $N_{\text {re }}$ is the number of cycles for fatigue crack re-initiation, and the coefficients $A$ and $B$ are empirical constants specific to the material system. From the re-initiation life data presented in Table $1, A=2 \times 10^{12}$ and $B=-6.1$. The actual crack re-initiation values from Table 1 and the predicted values for crack re-initiation as provided by the modified Correia Model are compared in Figure 8.

Figure 8 also illustrates the comparison between the modified Correia model and a correlation that crudely assumes $\Delta K_{\text {eff }}=\Delta K$. Both correlations exhibit confidence intervals in the vicinity of 95\% [32]. By taking into account crack closure, the modified Correia model exhibited a correlation constant of 12.3 as opposed to a value of 14.2 for the other correlation when crack closure was ignored. Based on these observations, it appears that when incorporating crack closure, the constant required to achieve a predictive correlation is reduced by approximately 13\%. Figure 9 illustrates a similar comparison with three other crack closure models for which the $U$ values are not equal to 1 . The re-initiation life predicted by each model were all close to actual values.

In Figure 9, the slopes for each trend were very similar, ranging from -6.1 (for the modified Correia model) to -6.3 (for all the others). The other constant in these curve fits showed more significant differences in between each of the models. The biggest difference was the large axis intercept value obtained in the curve fit that assumed no crack closure behavior. This constant was equal to

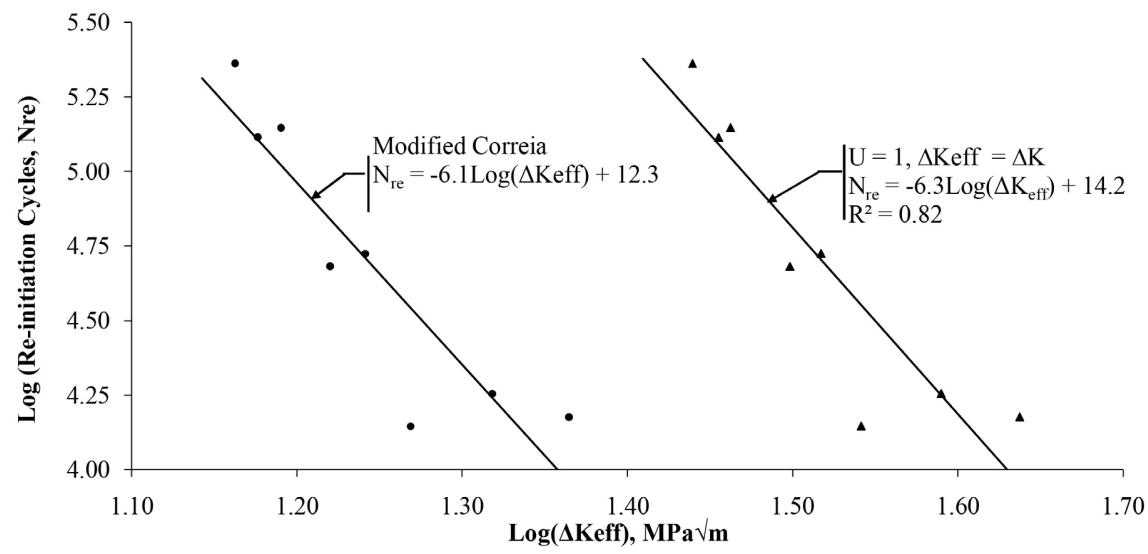

Figure 8. Log-log plot of the relationship between the effective stress intensity factor $\left(\Delta K_{\text {eff }}\right)$ and fatigue crack re-initiation life for modified Correia model and a special case when $\Delta K_{\text {eff }}$ equals to $\Delta K(U=1)$. 


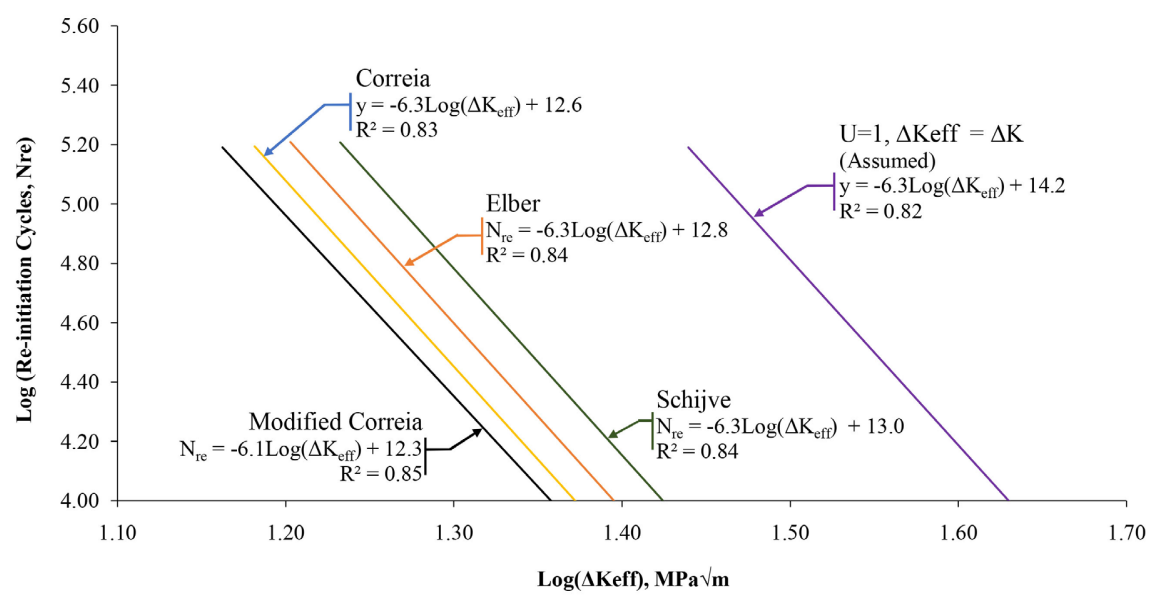

Figure 9. Log-log plot of the relationship between the effective stress intensity factor $\left(\Delta K_{\text {eff }}\right)$ and fatigue crack re-initiation life for Modified Correia, Correia, Elber, Schijve and a special case when $\Delta K_{\text {eff }}=\Delta K(U=1)$.

14.2. The other curve fits that incorporated crack closure models were exhibiting significantly lower axis intercept values $(13,12.8,12.6,12.3)$ clustered together. The Elber crack closure model exhibited an intercept value of 12.8 and required 2 empirical constants to calculate $\Delta K_{\text {eff }}$ The Schijve crack closure model exhibited an intercept value of 13.0 and required 3 empirical constants. Both the Correia and the modified Correia models exhibited lower intercept values of 12.6 and 12.3. Each of these crack closure models required 1 adjustable empirical constant. It can be argued that a lower number of empirical constants suggests evidence of a more rational predictive model. Another possible indicator of a relatively rational predictive model can be seen by examining the coefficients of the curve fit relationship between the crack re-initiation cycles and $\Delta K_{\text {eff }}$ of Figure 9. An interesting trend regarding these coefficients and empirical constants is evident. It appears that a reduction in empirical constants needed for the crack closure model (from 2 to 0 ) was accompanied by a reduction in the magnitude of the crack re-initiation axis intercept (from 13 to 12.3). Based on these observations, the low number of adjustable empirical constants in combination with the lowest magnitude of curve fit constants appears to indicate that the modified Correia model may provide the most rational basis for predicting the crack re-initiation behavior observed in this study.

In general, the localized induction of dislocation motion during fatigue cycling is believed to be a primary reason for crack initiation [33]. Similarly, the compressive stresses associated with fatigue striations coming into contact during crack closure may also induce localized dislocation motion. It is conceivable that this irreversible dislocation motion could lead to the degradation of the effect of plating-induced crack closure. Dislocation motion leading to the reduction of fatigue crack striation height could lead to the gradual increase of $\Delta K_{\text {eff }}$ to the point where crack propagation resumes.

Alternatively, it is conceivable that a treated crack may behave much as a notch, in which the behavior of the treated crack may be predicted by a strain-life 
approach [1]. Unfortunately, the strain-life approach would require additional adjustable constants and a value for $K_{t}$ (stress concentration factor) that would be difficult to define in this case due to the plated material influence. Hence, the fatigue crack re-initiation model based on crack closure would appear to be a more convenient, rational and less empirical approach as compared to using a strain life model to predict crack re-initiation.

In this study, it is notable that effective treatments were being applied even into crack openings that correlated to $K_{\max }$ values of only 3 - $6 \mathrm{MPa} \sqrt{\mathrm{m}}$. These values were in the vicinity of the $\Delta K_{\mathrm{th}}$ values (of $5-15 \mathrm{MPa} \sqrt{\mathrm{m}}$ ) that were reported in the literature [30]. For this steel, this treatment effectiveness suggests that these nearly closed cracks exhibited a topography that permitted the transmission of $\mathrm{Fe}^{2+}$ ions that were drifting in an electric field. It would be interesting to see if a completely unloaded crack could exhibit a similar topography, thus permit an effective crack arrest treatment. Based on these observations, it is recommended that future studies examine the effectiveness of treating unloaded cracks.

\subsection{Corrosion Susceptibility}

The material plated onto a crack surface tends to exhibit a nonuniform distribution because the electric field within a crack is nonuniform [25]. This inherent discontinuity allows for the dissimilar plated metal and the base metal to exhibit galvanic corrosion. This galvanic corrosion could be significant enough to cause irreversible damage and strength deterioration [34]. In contrast, a small corrosion rate can actually cause crack arrest [1]. Using iron as plated metal over steel was considered a better choice than nickel since it could create a lower galvanic potential that may result in a relatively low corrosion rate. The following sections explore the galvanic driving potentials and corrosion rates observed for this plating system. These evaluations were conducted using methods described earlier.

The galvanic potentials for the A36 steel observed with respect to the iron plated steel ranged from 162 to $192 \mathrm{mV}$. In this measurement, the $\mathrm{pH}$ value of the $3.5 \mathrm{wt} \% \mathrm{NaCl}$ solution was maintained at 6.8. The galvanic currents were measured by using a zero-resistance ammeter (ZRA). Using Equation (12), these measured currents were converted into corrosion rates expressed in mils per year (mpy) as,

$$
C R(\mathrm{mpy})=\frac{I_{c r} \times K \times E W}{d \times A},
$$

where $I_{c r}$ is the corrosion current in amperes, $K$ is a unit conversion constant equal to $1.29 \times 10^{5}, E W$ is the equivalent weight in gram/equivalent, $d$ is density in $\mathrm{g} / \mathrm{cm}^{3}$, and $A$ is the sample area in $\mathrm{cm}^{2}$. The anode to cathode surface area ratio was 1:4. The results of both the galvanic potentials and the galvanic corrosion rates observed are shown in Figure 10. The error bars pertain to a $90 \%$ confidence interval. 


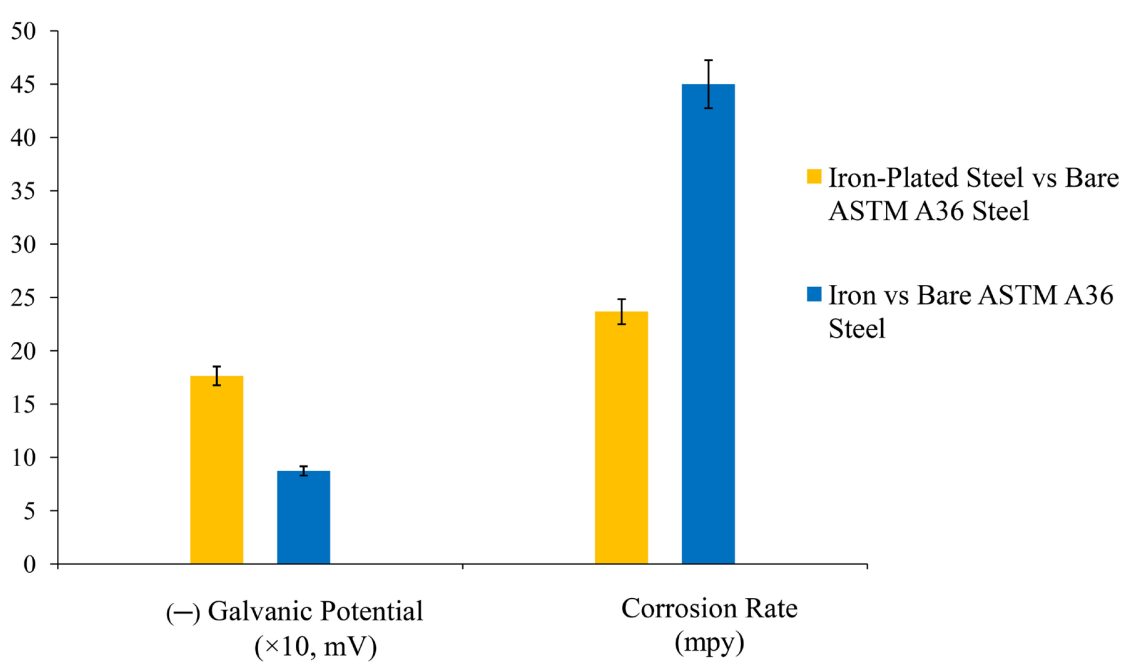

Figure 10. Galvanic potential and corrosion rates between the ASTM A36 steel and plated iron in $3.5 \mathrm{wt} \% \mathrm{NaCl}$ Solution. The listed corrosion potentials of the iron and plated iron were negative with respect to the ASTM A36 steel base metal.

In this study, the galvanic corrosion rate of the plated iron with respect to the A36 steel was 24 mpy for a 1:4 anode to cathode ratio. According to Aawaz's study, this galvanic corrosion rate could be reduced to $0.2 \mathrm{mpy}$ for an anode to cathode ratio of $25: 1$ that reflects a uniform plating layer that exhibits tensile cracks [6]. The current system would be expected to exhibit a higher rate due to the fact that the iron deposition would not likely be uniform. Ideally, a low corrosion rate would be on the order of 1 mpy or below. In order to reduce the corrosion rate further, it is conceivable that some degree of alloying of the plated metal could reduce the galvanic corrosion potential as well as the corrosion rate. Based on these observations, it is recommended that future work explore the possibility of depositing a plated alloy with a small amount of nickel in order to further reduce the galvanic corrosion potential of the system.

The corrosion of the plated iron (as indicated by Figure 10) is not likely to have direct impact on the base metal. During cyclic loading, the corrosion products of the plated metal would tend to build an oxide layer on the striation peaks (as shown in Figure 6). This thin oxide layer on top of these striations could cause the crack surfaces to close relatively sooner which could help extend the crack re-initiation life. The benefit obtained from this oxide layer may be short-lived as it is weaker than the base metal and could easily be broken up under this cyclic compression. Pitting and crevicing under the oxide could also tend to reduce fatigue and corrosion resistance of the base metal. In contrast, a limited oxygen availability within the crack tip would tend to inhibit such pitting and crevicing behavior within the crack.

\section{Conclusions and Recommendations}

This study focused on developing an electrochemical treatment to arrest fatigue crack propagation using iron plating. A modified crack closure model was also 
developed to predict the resulting crack re-initiation life. In this section, some conclusions and useful recommendations are drawn.

1) The electrochemical treatment succeeded in arresting the propagation of fatigue cracks for a useful period ranging from 11,000 to 370,000 cycles.

2) It was found possible to apply the treatment repeatedly and thus extend the fatigue life of A36 steel from 10\% - 60\%.

3) Treating cracks that are cycling at relatively low $\Delta K$ levels tended to result in higher crack re-initiation lives.

4) Relatively low plating treatment dosages may be ineffective in cases where $K_{\max }$ is in the vicinity of $K_{\mathrm{IC}}$ and crack closure effects have little influence.

5) The low number of adjustable crack-closure constants and the low magnitude of re-initiation curve fit constants indicate that the modified Correia model may provide the most rational version of the modeling options considered.

6) It is recommended that future studies examine the effectiveness of treating unloaded cracks.

7) Further work is recommended to determine when timely re-application of the treatment (prior to crack re-initiation) could further cause crack propagation to remain arrested indefinitely.

8) There is a need to study the impact of corrosion on the plated metal of a treated crack. Future work could involve both treating and cycling in various environments, $\Delta K$ values, and $R$ ratios.

9) It is recommended that future work explore the possibility of depositing a plated iron alloy with a small amount of nickel in order to reduce the galvanic corrosion potential.

\section{Conflicts of Interest}

The authors declare no conflicts of interest regarding the publication of this paper.

\section{References}

[1] Bannantine, J. (1990) Fundamentals of Metal Fatigue Analysis. Prentice Hall, Englewood Cliffs, NJ.

[2] Kondo, Y. (2003) Comprehensive Structural Integrity: Volume 4-Cyclic Loading and Fatigue. In: Milne, I., Ritchie, R.O., Karihaloo, B. and Murakami, Y., Eds., Fatigue under Variable Amplitude Loading, Elsevier Pergamon, Amsterdam, 253-280.

[3] Song, P.S., Sheu, B.C. and Chou, H.H. (2001) Deposition of Plating Metals to Improve Crack Growth Life. International Journal of Fatigue, 23, 259-270. https://doi.org/10.1016/S0142-1123(00)00084-0

[4] Shin, C.S. and Chen, Z.Z. (2001) Fatigue Life Extension by Electroless Nickel Infiltration Plating. International Journal of Fatigue, 32, 777-788. https://doi.org/10.1016/S0142-1123(01)00038-X

[5] Dolgan, K. (2015) Electrochemical Treatment of Fatigue Cracks. Ph.D. Thesis, Louisiana Tech University, Ruston, LA.

[6] Cardenas, H. and Shrestha, A. (2018) Protective Characteristics of Electroplated Iron Applied to Low Carbon Steel. AIP Conference Proceedings, Sliema, 22-24 June 
2018, 22-25. https://doi.org/10.1063/1.5060698

[7] Pugno, N., Ciavarella, M., Cornetti, P. and A. Carpinteri, A. (2006) A Generalized Paris' Law for Fatigue Crack Growth. Journal of the Mechanics and Physics of Solids, 54, 1333-1349. https://doi.org/10.1016/j.jmps.2006.01.007

[8] Furmanski, J. and Pruitt, L.A. (2018) Static Mode Fatigue Crack Propagation and Generalized Stress Intensity Correlation for Fatigue-Brittle Polymers. International Journal of Fracture, 210, 213-221. https://doi.org/10.1007/s10704-018-0267-x

[9] Hussain, K. (1997) Short Fatigue Crack Behavior and Analytical Models: A Review. Engineering Fracture Mechanics, 58, 327-354.

https://doi.org/10.1016/S0013-7944(97)00102-1

[10] Forman, R.G., Kearney, V.E. and Engle, R.M. (1967) Numerical Analysis of Crack Propagation in Cyclic-Loaded Structures. Journal of Basic Engineering, 89, 459-463. https://doi.org/10.1115/1.3609637

[11] Kim, C. and Kwang-Woo, C. (2012) A Study on Fatigue Crack Propagation of Rail Steel under Constant and Mixed Mode Variable Amplitude Loadings. International Journal of Railway Transportation, 5, 71-76. https://doi.org/10.7782/IJR.2012.5.2.071

[12] Elber, W. (1970) Fatigue Crack Closure under Cyclic Tension. Engineering Fracture Mechanics, 2, 37-45. https://doi.org/10.1016/0013-7944(70)90028-7

[13] Elber, W. (1971) The Significance of Fatigue Crack Closure. In: Rosenfeld, M., Ed., Damage Tolerance in Aircraft Structures, ASTM International, West Conshohocken, PA, 230-242. https://doi.org/10.1520/STP26680S

[14] McEvily, A.J. and Ritchie, R.O. (1998) Crack Closure and the Fatigue-Crack Propagation Threshold as a Function of Load Ratio. Fatigue \& Fracture of Engineering Materials \& Structures, 21, 847-855. https://doi.org/10.1046/j.1460-2695.1998.00069.x

[15] Grasso, M., De Iorio, A., Xu, Y., Mohin, M. and Chen, Y. (2017) An Analytical Model for the Identification of the Threshold of Stress Intensity Factor Range for Crack Growth. Advances in Materials Science and Engineering, 2017, Article ID: 3014172. https://doi.org/10.1155/2017/3014172

[16] Schijve, J. (2008) Fatigue of Structures and Materials. 2nd Edition, Springer, Netherlands.

[17] Correia, J., Jesus, A., Moreira, P. and Tavares, P. (2016) Crack Closure Effects on Fatigue Crack Propagation Rates: Application of a Proposed Theoretical Model. Advances in Materials Science and Engineering, 2016, Article ID: 3026745. https://doi.org/10.1155/2016/3026745

[18] Maierhofer, J., Kolitsch, S., Pippan, R., Gänser, H.P., Madia, M. and Zerbst, U. (2018) The Cyclic R-Curve-Determination, Problems, Limitations and Application. Engineering Fracture Mechanics, 198, 45-64. https://doi.org/10.1016/j.engfracmech.2017.09.032

[19] Zerbst, U., Vormwald, M., Pippan, R., Gänser, H.P., Sarrazin-Baudoux, C. and Madia, M. (2016) About the Fatigue Crack Propagation Threshold of Metals as a Design Criterion-A Review. Engineering Fracture Mechanics, 153, 190-243. https://doi.org/10.1016/j.engfracmech.2015.12.002

[20] Zerbst, U., Madia, M., Klinger, C., Bettge, D. and Murakami, Y. (2019) Defects as a Root Cause of Fatigue Failure of Metallic Components. Part I: Basic Aspects. Engineering Failure Analysis, 97, 777-792. https://doi.org/10.1016/j.engfailanal.2019.01.055

[21] Pippan, R. and Hohenwarter, A. (2017) Fatigue Crack Cosure: A Review of the 
Physical Phenomena. Fatigue \& Fracture of Engineering Materials \& Structures, 40, 471-495. https://doi.org/10.1111/ffe.12578

[22] Maierhofer, J, Gänser, H.P. and Pippan, R. (2017) Crack Closure and Retardation Effects-Experiments and Modelling. Procedia Structural Integrity, 4, 19-26. https://doi.org/10.1016/j.prostr.2017.07.014

[23] Mordechay, S. and Milan, P. (2010) Modern Electroplating. Wiley-Blackwell, Hoboken, NJ.

[24] Saleem, H. (2016) Introduction to Surface Coating Processes. In: Choudhury I.A. and Hashmi, M.S.J., Eds., Comprehensive Materials Finishing, Elsevier Science, Kidlington, 358-381.

[25] Paunovic, M. and Schlesinger, M. (2006) Fundamentals of Electrochemical Deposition. 2nd Edition, John Wiley \& Sons, Inc., Pennington, NJ. https://doi.org/10.1002/0470009403

[26] Popov, B.N. (2015) Corrosion Engineering: Principles and Solved Problems. Elsevier, Amsterdam, 239-287. https://doi.org/10.1016/B978-0-444-62722-3.00006-9

[27] ASTM E399 (2009) Standard Test Method for Linear-Elastic Plane-Strain Fracture Toughness KIc of Metallic Materials. ASTM International, West Conshohocken, PA.

[28] Yang, L. and Yang, A. (2017) Communication-On Zero-Resistance Ammeter and Zero-Voltage Ammeter. Journal of the Electrochemical Society, 164, Article ID: C819. https://doi.org/10.1149/2.1421713jes

[29] Yang, L. (2008) Techniques for Corrosion Monitoring. Woodhead Publishing, Cambridge, 111-126.

[30] Barsom, J.M. and Rolfe, S.T. (1999) Fracture and Fatigue Control in Structures: Application of Fracture Mechanics. 3rd Edition, ASTM International, West Conshohocken, PA. https://doi.org/10.1520/MNL41-3RD-EB

[31] Barsom, J.M. (1971) Fatigue-Crack Propagation in Steels of Various Yield Strengths. Journal of Manufacturing Science and Engineering, 93, 1190-1196. https://doi.org/10.1115/1.3428061

[32] Ganji, A.R. and Wheeler, A.J. (1996) Introduction to Engineering Experimentation. Prentice Hall, Englewood Cliffs, NJ.

[33] Campbell, L. (1977) Effect of Dislocation Substructures on Fatigue Fracture. Metallurgical Transactions A, 8, 851-860. https://doi.org/10.1007/BF02661566

[34] Qian, S. and Qu, D. (2010) Theoretical and Experimental Study of Galvanic Coupling Effects between Carbon Steel and Stainless Steels. Journal of Applied Electrochemistry, 40, 247-256. https://doi.org/10.1007/s10800-009-9998-8 